2) Herniaria glabra.

$\begin{array}{cc}\text { Von Kiesel- } & \text { bo } \\ \text { boden. } & \begin{array}{c}\text { Von Dolomit- } \\ \text { boden. }\end{array}\end{array}$

Ausbeute der lufttrocknen Pflanzen

an Asche

$$
\text { 7,132 Proc. 6,622 Proc. }
$$

Procentische Zusammensetzung der Aschen.

\begin{tabular}{|c|c|c|c|c|}
\hline Kali & $24,380 \mathrm{P}$ & Proc. & $8,680 \mathrm{H}$ & Proc. \\
\hline Natron & 4,110 & , & 3,860 & $"$ \\
\hline Natrium (mit dem Chlor verbunden) & 1,702 & " & 0,691 & $"$ \\
\hline Kalk & 14,349 & $"$ & 30,400 & $"$ \\
\hline Magnesia & 6,300 & " & 14,839 & $\eta$ \\
\hline Alaunerde & 1,321 & $"$ & 1,755 & $"$ \\
\hline Eisenoxyd & 1,038 & $"$ & 0,430 & $"$ \\
\hline Manganoxyduloxyd & - & & - & \\
\hline Chlor & 2,624 & ” & 1,066 & , \\
\hline Schwefelsäure & 1,717 & $"$ & 1,746 & $"$ \\
\hline Phosphorsäure & 9,729 & " & 8,421 & , \\
\hline Kieselsäure & 14,445 & $"$ & 6,367 & $"$ \\
\hline Kohlensäure & 17,694 & $"$ & 21,505 & $"$ \\
\hline Summa & 99,409 . & & 99,760 . & \\
\hline
\end{tabular}

\title{
Mittel zur Erkennung der Mineralsäuren im Essig.
}

\section{Yon Strobl.}

Dieses Mittel gründet sich auf die Unlöslichkeit des oxalsauren Kalks in verdünnter Essigsäure und dessen Löslichkeit in verdünnten Mlineralsäuren. Das hier zu verwendende Reagens ist daher der oxalsaure Kalk. Da die Reagentien um so empfindlicher, je frischer sie sind, so muss man dahin trachten, den oxalsauren Kalk erst in dem Augenblicke zu erzeugen, wo er wirken soll, indem man nemlich in die zu untersuchende Flüssigkeit bestimmte Mengen aufgelösten oxalsauren Ammoniaks und Chlorcalciums giesst. Da sie aber um so sauerer sein muss, je mehr oxalsaurer Kalk aufzủlösen 
ist, und da folglich der Grad der Empfindlichkeit der Methode mit der Menge des zugesetzten Reagens abnimmt, auch ein Ueberschuss des einen oder andern der beiden Salze vermieden werden muss, so hat man die beiden Solutionen der Reagentien so herzustellen, dass sie die nachstehenden Bedingungen erfüllen:

1) Sich in gleichen Raumtheilen genau zu neutralisiren;

2) So verdünnt zu sein, dass nur eine Trübung eintreten kann, aber eine sehr deutliche in von Mineralsäuren freiem Essig erfolgt.

Darstellung des Reagens. Durch eine Reihe von Versuchen habe ich gefunden, dass $1 / 5$ Aequivalent eines jeden in Wasser bis zu 1 Liter Verdünnung gelösten Salzes Flüssigkeiten giebt, welche den verlangten Bedingungen entsprechen, d. h. 1/2 C.C. Lösung des oxalsauren Ammoniaks und $1 / 2$ C.C. Lösung des Chlorcaloiums geben zu 50 C.C., von Mineralsäuren freiem Essig gesetzt eine sehr deutliche Trübung.

Darstellung der titrirten sauren Flüssigkeiten. Von dem gewöhnlich vorkommenden Fälschungsgrade des Essigs mit Mineralsäuren ansgehend, stellte ich Flüssigkeiten dar, welche in jedem C.C. 2 Centigr. wasserfreie Säure enthalten. $\mathrm{Zu}$ diesen $Z_{w}$ wecke prüfte ich die zu verwendenden Säuren erst auf ihr specifisches Gewicht und ersah dann aus den Tabellen von Bineau, Ure etc. ihren Procentgehalt an wasserfreier Säure. Angenommen, das spec. Gew. der Schwefelsäure habe 1,841 ergeben, so weisen die Tabellen aus, dass darin 80 Proc. wasserfreie Säure enthalten sind. Will man nun daraus eine Flüssigkeit herstellen, welche per C.C. 2 Centig. oder, was dasselbe ist, in 100 C.C. 2 g. $\mathrm{SO}^{3}$ enthält, so setzt man an:

$$
100: x=80: 2
$$

und bekommt

$$
\mathrm{x}=\frac{100 \times 2}{80}=2,5,
$$

d. h. man bedarf für 100 C.C. Flüssigkeit $2,5 \mathrm{~g}$. Säure von obigem Gehalte. 
Ebenso verfährt man bei der Anfertigung der übrigen verdünnten Säuren.

Bestimmung der Grenzeder Empfindlichkeit für die verschiedenen $\mathbf{S}$ äuren. Man giesst in einen Reagirkelch 50 C.C. Essig, setzt dazu $1 / 8$ C.C. von jeder der beiden Solutionen, welche bei ihrem Zusammentreffen oxalsauren Kalk bilden, und erhält dadurch eine sehr deutliche Trübung. Hierauf tröpfelt man aus einer in $1 / 10$ C.C. getheilten Bürette von der titrirten Säure so lange hinzu, bis die Trübung wiederum vollständig verschwunden ist. Angenommen, es seien dazu 6 C.C. erforderlich gewesen. Man wiederholt nun den Versuch, jedoch mit dem Unterschiede, dass zuerst die Säure und in kleinerer Menge in den Essig kommt; man setzt z. B. 4 C.C. Säure zu 46 C.C. Essig, und dann erst das Reagens ( $1 / 2$ C.C. oxalsaure Ammoniaklösung und $1 / 2$ C.C. Chlorcalciumlösung). Wenn die Trübung sofort wieder verschwindet, so waren 4 C.C. Säure zu viel, und man wiederholt den Versuch mit weniger Säure. Bleibt aber die Trübung, so repetirt man mit mehr als 4 C.C. Säure.

Auf diese Weise gelangt man zuletzt an die äusserste Grenze der Empfindlichkeit für jede der Säuren. So ergab sich für die Salpetersäure, von der man anfangs 6,5 C.C. gebraucht hatte, als Grenze 5 C.C.

Als Grenzen fand man:

$\begin{array}{cll}\text { Für die Salzsäure } & 2,5 \text { C. C. } \\ " \quad \text { "Salpetersäure } & 5,0 \text { " } \\ \text { " Schwefelsäure } & 3,5 \%\end{array}$

Da jede dieser verdinnten Säuren in 1 C.C. 2 Centig. wasserfreie Säure enthält, so reichen

5 Centig. wasserfreie Salzsäure $(\mathrm{HCl})$,

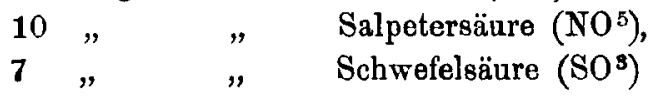

in 50 C.C. Essig hin, um zu verhindern, dass derselbe durch den Zusatz des oxalsauren Kalks (resp. des zu seiner Entstehung angewandten Reagens) eine Trübung erleidet. 
Mit andern Worten:

5 Centig. wasserfreie $\mathrm{HCl}$

$\begin{array}{ccc}10 " & \Rightarrow & \mathrm{NO}^{5} \\ \text { und } 7 & " & \mathrm{SO}^{3}\end{array}$

können in 50 C.C. Essig erkannt werden, oder, wenn man mit 20 multiplicirt,

in 1 Liter Essig.

$\begin{array}{rrr}1 \text { g. wasserfreie } & \mathrm{HCl} \\ 2, & " & \mathrm{NO}^{5} \\ \text { und } 1,4, & " & \mathrm{SO}^{3}\end{array}$

Die Grenze der Empfindlichkeit für die gewöhnlich im Handel vorkommenden Säuren ist

Für die Salzsäure von 1,174 spec. Gew. $1,0 \times 2,85=2,85 \mathrm{~g}$. " "Salpetersäure " 1,330 " " $2,0 \times 2,2=4,40$ " " "Schwefelsäure, 1,843 " " $\quad 1,4 \times 1,22=1,71$ "

Um also die Gegenwart einer Mineralsäure im Essig zu erkennen, setzt man zu 50 C.C. desselben $1 / 2$ C. C. oxalsaure Ammoniaklösung und $1 / 2$ C.C. Chlorcalciumlösung, von denen jede im Liter $1 / 5$ Aeq. Salz enthält, nemlich vom oxalsauren A mmoniak $\left(\mathrm{NH}^{4} \mathrm{O}+\mathrm{C}^{2} \mathrm{O}^{3}\right)^{71 / 5}=14,2 \mathrm{~g}$., und rom Chlorcalcium $(\mathrm{CaCl}) 55 / 5=11 \mathrm{~g}$.

Verschwindet die anfangs entstandene Trübung nicht wieder vollständig, so enthält der Essig per Liter weniger als

$$
\begin{aligned}
& 2,85 \mathrm{~g} \text {. Salzsäure, oder } \\
& 4,40 \text { "Salpetersäure, oder } \\
& 1,70 \text { " Schwefelsäure. }
\end{aligned}
$$

Tritt aber wieder völlige Klarheit ein, so enthält er mindestens so viel von der einen oder anderen Mineralsäure. (Journ. de Pharm. et de Chim., Sept. 1874, XX. 172. Vergl. S. 193. Mittheilungen von Prof. Hilger). 